\title{
Author Correction: Midbrain circuit regulation of individual alcohol drinking behaviors in mice
}

\author{
Barbara Juarez ${ }^{1,2}$, Carole Morel ${ }^{1}$, Stacy M. Ku,2, Yutong Liu1, Hongxing Zhang ${ }^{1,3}$, Sarah Montgomery ${ }^{1,2}$, \\ Hilledna Gregoire ${ }^{1}$, Efrain Ribeiro², Marshall Crumiller², Ciorana Roman-Ortiz², Jessica J. Walsh', Kelcy Jackson? \\ Denise E. Croote ${ }^{1}$, Yingbo Zhu', Song Zhang ${ }^{1}$, Leandro F. Vendruscolo ${ }^{4}$, Scott Edwards ${ }^{5}$, Amanda Roberts ${ }^{6}$, \\ Georgia E. Hodes ${ }^{2}$, Yongke Lu,8, Erin S. Calipari ${ }^{2,9}$, Dipesh Chaudhury ${ }^{1,10}$, Allyson K. Friedman (1) ${ }^{1,11} \&$ \\ Ming-Hu Han ${ }^{1,2}$
}

Correction to: Nature Communications https://doi.org/10.1038/s41467-017-02365-8, published online: 20 Dec 2017

The original version of this Article contained an error in the spelling of the author Scott Edwards, which was incorrectly given as Scott Edward. This has now been corrected in both the PDF and HTML versions of the Article.

Published online: 08 February 2018 \begin{abstract}
reproduction in any medium or format, as long as you give appropriate credit to the original author(s) and the source, provide a link to the Creative Commons license, and indicate if changes were made. The images or other third party material in this article are included in the article's Creative Commons license, unless indicated otherwise in a credit line to the material. If material is not included in the article's Creative Commons license and your intended use is not permitted by statutory regulation or exceeds the permitted use, you will need to obtain permission directly from the copyright holder. To view a copy of this license, visit http://creativecommons.org/licenses/by/4.0/.
\end{abstract}

(c) (1) Open Access This article is licensed under a Creative Commons Attribution 4.0 International License, which permits use, sharing, adaptation, distribution an

() The Author(s) 2018

\footnotetext{
${ }^{1}$ Department of Pharmacological Sciences and Institute for Systems Biomedicine, Icahn School of Medicine at Mount Sinai, New York, NY 10029, USA.

${ }^{2}$ Fishberg Department of Neuroscience and Friedman Brain Institute, Icahn School of Medicine at Mount Sinai, New York, NY 10029, USA. ${ }^{3}$ Jiangsu Province Key Laboratory of Anesthesiology, Xuzhou Medical University, Xuzhou 221002 Jiangsu, China. ${ }^{4}$ Intramural Research Program, National Institute on Drug Abuse, National Institutes of Health, Baltimore, MD 21224, USA. ${ }^{5}$ Department of Physiology, Alcohol and Drug Abuse Center of Excellence, Neuroscience Center of Excellence, Louisiana State University Health Sciences Center, New Orleans, LA 70112, USA. ${ }^{6}$ Department of Molecular and Cellular Neuroscience, The Scripps Research Institute, San Diego, CA 92037, USA. ${ }^{7}$ Department of Medicine, Icahn School of Medicine at Mount Sinai, New York, CA 10029, USA. ${ }^{8}$ Department of Health Sciences, College of Public Health, East Tennessee State University, Johnson City, TN 37614, USA. ${ }^{9}$ Department of Pharmacology, Vanderbilt University, Nashville, TN 37232, USA. ${ }^{10}$ Division of Science, New York University Abu Dhabi (NYUAD), Saadiyat Island Campus, Abu Dhabi PO Box 129188, United Arab Emirates. ${ }^{11}$ Department of Biological Sciences, Hunter College, City University of New York, New York, NY 10065, USA Correspondence and requests for materials should be addressed to M.-H.H. (email: ming-hu.han@mssm.edu)
} 